\title{
REFLEXIONES ACERCA DE LA ENSEÑANZA DE LA LITERATURA EN LAS CLASES DE ESPAÑOL COMO SEGUNDA LENGUA: UNA NUEVA DESTREZA POR DESARROLLAR A PARTIR DE UNA NUEVA PROPUESTA METODOLÓGICA
}

\author{
Ana Elena Castillo V.
}

\begin{abstract}
RESUMEN
En el artículo se propone una nueva metodología para enseñar literatura a estudiantes hablantes no nativos del español, cuya finalidad es brindarle al alumno herramientas teóricas y pautas para hacer un análisis textual fundamentado y, así, motivarlo a leer. Se establece una nueva destreza por desarrollar en el campo de lo literario: la destreza analítica.

Palabras clave: enseñanza de la literatura, extranjeros, nueva metodología, destreza analítica, habilidad reflexiva, función ideológica.
\end{abstract}

\begin{abstract}
The aim of this article is to propose a new methodology for Latinamerican literature teaching to nonnative speakers. This method would provide students with theory and analytical strategies to do textual analysis and, ultimately, motivate them to read. A new skill to develop is established for the literary field: analytical proficiency.

Key words: teaching literature, foreign, new methodology, analytical skill, thoughtful ability, ideological function.
\end{abstract}

\section{Introducción}

Al comienzo de la clase, la maestra nos hizo leer una historia cuyo contexto a mi forma de ver no era el más apropiado, pero como ella dijo una vez "no hay malos libros sino malos lectores", desafortunadamente yo caí en ese error... esa misma tarde mis limitadas fronteras literarias fueron abiertas a un sinnúmero de incógnitas.

El comentario anterior, escrito en una carta a un coordinador académico después de analizar un cuento, deja entrever un problema muy frecuente cuando hablamos de enseñar la

\footnotetext{
Ana Elena Castillo V. Profesora de la Escuela de Estudios Generales de la Universidad de Costa Rica. San Pedro, San José, Costa Rica

Correo electrónico: anaelcastillo@ hotmail.com
}

Recepción: 02-03-04

Aceptación: 10-03-04 
literatura. Y es que la pregunta no se deja esperar, por lo menos en la mente de quien debe tomar una clase de éstas: ¿para qué la literatura?

No obstante, la pregunta muestra un problema de fondo aún mayor y es que, para la mayoría, la literatura, además de ser inútil, es sobretodo muy tediosa, aburrida, sin sentido y, en el mejor de los casos, sirve solo para reforzar un mito social por medio del cual una persona conocedora de ciertos libros se percibe como educada y culta (esto si hablamos desde la definición de cultura propuesta en la época de la ilustración por Johan von Herder). En otras palabras, el estudio de la literatura se ve como un lujo que algunas personas adquieren pero que, fuera de un conocimiento superficial, no pasa de ser un adorno, algo carente de importancia, que no afecta al individuo y que socialmente se torna irrelevante.

Es necesario entonces cuestionarse la forma en que ha sido tratada la literatura, la forma como se ha enseñado, ya que las características que se asocian a ella indisponen de antemano al estudiante que se enfrenta a una clase literaria. Es decir, la metodología que se ha utilizado en el estudio de la literatura tiene relación directa con los adjetivos calificativos mencionados anteriormente: inútil, superficial, irrelevante; por lo tanto, el estudiante ve las clases como aburridas y tediosas. El problema se produce, entonces, en dos sentidos: un objeto de estudio poco útil y una metodología que refuerza este concepto.

El presente artículo ahondará precisamente en este punto, ya que se busca esbozar la propuesta de una metodología que motive la lectura de la literatura y brinde elementos para su análisis. Contrario a lo que se podría pensar, los estudiantes hablantes no nativos arrastran igualmente estos prejuicios y, a la hora de enfrentarse a la literatura de otra lengua, el panorama empeora, ya que sienten inseguridad lingüística y no tienen, en su mayoría, las herramientas teóricas que permitan un análisis serio pero motivador para involucrarse activamente en la lectura de los textos. Como bien lo expresaba en la cita inicial, la estudiante se sentía limitada, incapaz de poder ir más allá, con un vacío muy grande de conocimientos o "rutas" para ser una lectora ágil y lograr "adentrarse" en los textos activamente.

Es común escuchar que la literatura no es importante dentro de los planeamientos en la enseñanza de una lengua extranjera. Una de las razones primordiales que sustenta tal afirmación es la creencia de que, cuando enseñamos un idioma, debemos enfocarnos en el ámbito de la gramática, del vocabulario y, en última instancia, la fonología. Este criterio aplica tanto para niveles principiantes como avanzados. La lengua, el español en este caso, se concibe como un idioma compuesto por estos elementos. Los estudiantes van aprendiéndolo poco a poco y cuando llegan al nivel avanzado deben, básicamente, perfeccionar la lengua, es decir, aumentar la fluidez, dominar cada vez más la gramática, ampliar y usar el léxico y pronunciar mejor.

Evidentemente, la literatura queda relegada, por no decir descartada, dentro de los planeamientos de clase. En todo caso, algunos profesores optan por "utilizarla" para ejemplificar alguna estructura gramatical o mostrar el vocabulario que les interesa. Para tal efecto, toman un fragmento de una novela, un cuento o una poesía. Otros la usan para enseñar cultura pero, incluso en este aspecto, algunos teóricos importantes como David Seley (1994: 17) afirman categóricamente que esto es un error y que la literatura no debe ser utilizada para enseñar cultura. El riesgo radica en transmitir estereotipos y en complicar la comprensión de la cultura debido a la época histórica que enmarcó la obra. Finalmente, afirma, con cierto excepticismo: "la literatura puede verse en el presente contexto como una ilustración de los patrones culturales de la sociedad una vez que esos patrones han sido identificados por medio de los métodos de 
las ciencias sociales” (1994: 18). En síntesis, si se opta por incluir lo literario en la clase, se hace con una idea en la mente muy clara: la literatura es un medio.

En nuestro artículo, se justifica la propuesta de una nueva metodología al considerar la literatura como un objeto de estudio por sí misma, no como un medio. Los textos literarios y sus respectivos análisis son riquísimos en sí y proporcionan al estudiante un conocimiento y una habilidad reflexiva importante dentro de su competencia. Además, los alumnos hablantes no nativos del español de un nivel avanzado pueden interesarse tanto en la literatura como un hablante nativo. De la literatura y de la forma en cómo ésta se enseñe va a depender que el alumno continúe estudiándola y lo haga motivado. Se tendría la ventaja de estar desarrollando constantemente la destreza de la lectura.

Debido a esto, surge nuestro interés en desarrollar una metodología para enseñar la literatura. Los beneficios que se puedan desprender del estudio literario (como aumento del léxico o de las estructuras gramaticales) serán ventajas adicionales, pero lo importante es situar la literatura como un objeto de estudio que es parte importante dentro de los planeamientos de clase de los hablantes no nativos del español.

\section{De lo dicho por otros autores acerca de la enseñanza de la literatura en las clases de español para extranjeros}

Es indispensable hacer una revisión de algunas de las propuestas sobre el tema de la enseñanza de la literatura en las clases de español como segunda lengua, tanto en libros como en artículos, de forma tal que sirva de antecedente a la propuesta metodológica. Esto es fundamental pues se busca encontrar puntos de concordancia o de divergencia que nos brinden parámetros para determinar cuál ha sido la posición general en cuanto a la forma de enseñar la literatura.

En este sentido, uno de los primeros artículos consultados fue "Introducing literature: some points of departure". En él, Michael L. Noricks (2003: 1) afirma que los estudiantes estadounidenses de secundaria y universitarios frecuentemente no tienen la suficiente competencia o seguridad para lograr estudiar la literatura hispanoamericana con éxito. El problema radica en que, según el autor, saber leer literatura es un paso crucial para la adquisición de un segundo idioma. Por lo tanto, es muy importante presentarla de una manera estimulante. En esencia, la literatura debe ser utilizada como un medio y no como un mensaje. Ésta no debe ser un fin en sí misma sino un medio por el cual los estudiantes puedan aumentar su confianza y competencia. Con el fin de lograrlo, propone una rutina de cuatro pasos: la primera parte es una conversación guiada con preguntas de discusión que "incentiven" lingüísticamente la clase. En la segunda parte, se asigna como tarea un párrafo de resumen sobre las lecturas por tratar. La actividad puede variar si se le pide al alumno hacer preguntas originales sobre las lecturas y redactar sus respectivas respuestas. El tercer punto es de discusión. Un alumno es escogido al azar y evalúa a los estudiantes con el material asignado. El rol del profesor se reduce a corregir sólo los errores gramaticales o de información más graves. Finalmente, se desarrolla un período de preguntas y discusión, dependiendo de las dudas que pudieran tener los alumnos. "Un paso indispensable, si un estudiante desea adquirir un segundo idioma, es la lectura de la literatura; por lo tanto, se debe reforzar e insistir en ella mediante una rutina que los dirija a esta meta” (Noricks 2003: 1). 
Al partir de estas sugerencias, podemos afirmar que utilizar la literatura como un medio para aumentar la competencia lingüística de los estudiantes hablantes no nativos de una segunda lengua es relegar su posición; no puede contribuir a romper con los estereotipos negativos, lo cual fomenta, a su vez, las actitudes negativas: se ve la literatura como un medio tedioso para conseguir el dominio gramatical y la comprensión de la segunda lengua.

Edelma N. de Gallardo, en su libro Guía práctica para enseñar español a extranjeros (1995), propone utilizar el cuento como ayuda didáctica. Nuevamente, nos encontramos con uno de los géneros literarios pero utilizado como medio y como apoyo didáctico. Lo que se puede estudiar (lo importante, diríamos) es el uso de la lengua, el conocimiento de la cultura, el contacto con la lengua literaria y el lenguaje coloquial. La autora sugiere que se busquen cuentos cortos que tengan descripciones del paisaje local para que los estudiantes puedan conocer después los lugares en cuestión; tal es el caso de Escazú, por medio del cuento de Carlos Salazar Herrera "La bruja”.

En cuanto a los personajes, se pide enfatizar las diferencias culturales con otros países y reforzar lo que ella llama nuestra isla cultural. Las metáforas se interpretarán con el fin de aumentar el vocabulario de los estudiantes y, en palabras de la autora, "entrar en el lenguaje figurativo que en forma vital se produce también en el lenguaje coloquial" (103). Agrega que se puede interrogar al alumno acerca de las situaciones presentadas en el cuento y si algunas de éstas se reproducen en sus respectivas comunidades, apartando las que son propias del "mundo latino". Finalmente, sugiere otra actividad en la cual se les solicita a los estudiantes hacer "símiles coloquiales", es decir, usar hipérboles de los cuentos en el lenguaje coloquial. Además, el cuento, afirma la autora, sirve para reforzar el uso de la gramática, pues se pueden hacer preguntas del tipo ¿Por qué el escritor usó el potencial y no el futuro?

Es evidente que, en una propuesta así, lo menos que se está estudiando es la literatura. Pedir a los estudiantes que lean las descripciones del paisaje para que después lo vean en la realidad y proceder igual con situaciones cotidianas no hace más que confundir, ya que se está forzando a comparar la literatura con lo real, y "un real" de otro siglo, y se excluyen explicaciones de cambios importantes y fenómenos histórico-sociales que modifican radicalmente, no solo la fisionomía de un lugar, sino la dinámica de las relaciones sociales. La verosimilitud en la literatura no deja de ser una estrategia textual utilizada en cierto momento, un recurso más para hacer creíble un relato. Sin embargo, esto no es analizar la literatura, y aún menos si no se aclara que estamos solamente ante una herramienta del escritor. Aparte de las reservas en cuanto si es o no adecuado utilizar el lenguaje literario para enseñar lenguaje coloquial, lo cierto es que la posición se mantiene: la literatura continúa siendo un medio para y no un objeto de estudio. Hablar del mundo latino o la isla cultural que es Costa Rica no es, definitivamente, la posición más seria y fundamentada para aproximarse a la enseñanza de la cultura y, por supuesto, no lo es para estudiar la literatura. Al final, se utilizan las oraciones que componen el cuento para enseñar gramática.

Otra propuesta, esta vez más específica, de cómo enfrentarse a un texto, en este caso a la novela Pedro Páramo, la hace Carol Clark D’Lugo (1986: 12) en su artículo Pedro Páramo: The reader's Journey through the text. Ella afirma que Juan Rulfo presenta una alegoría sobre cómo leer con el texto y dentro de él. Para ilustrar este proceso, la autora enfoca el análisis en dos aspectos fundamentales: el señalamiento de las etapas por las cuales pasan los lectores mientras trabajan los fragmentos y el establecimiento del proyecto textual paralelamente a la liberación del lector. Al examinar cómo el autor ha construido el segmento de una 
novela confusa se demostrará cómo Rulfo crea, a través de las estrategias textuales, una dependencia entre el lector y Juan Preciado, y entonces, al subvertir este lazo, fuerza al lector a una aceptación del mismo discurso a la vez que lo impulsa hacia una experiencia literaria completa.

Mediante el personaje de Juan Preciado podemos insertar al lector en una experiencia literaria completa, los estudiantes se adentrarán en el texto y su discurso plenamente (D’Lugo 1986: 12).

Tomando en cuenta lo descrito anteriormente, esta perspectiva tiene la ventaja de ver el texto literario como un objeto de estudio y enfocarse en el proceso de lectura por medio del cual el lector logra involucrarse y participar activamente dentro de las estrategias textuales que hay en la novela, y esto, por decir lo menos, es ya un gran acierto. No obstante, hacen falta las herramientas teóricas necesarias para que un estudiante pueda aplicarlas en otros textos y continuar involucrado en el estudio literario.

Sin duda, involucrar y motivar al lector son objetivos claros y enriquecedores que no están presentes en muchos libros como los de Español lengua extranjera: textos literarios y ejercicios. Nivel avanzado y superior. Bados Ciria (2001) propone una metodología tradicional, ya que recopila cuentos cortos, muestra una pequeña biografía del autor, una lista de vocabulario básico y termina con una práctica de ejercicios gramaticales y de comprensión al final de cada uno de los relatos. Este tipo de aproximación tradicional evidentemente no logra involucrar, valga la insistencia, al lector con el texto, tal y como lo plantea la teoría de la recepción: el texto existe hasta que un lector lo lee y participa activamente en su lectura, para así lograr disfrutarla y compenetrarse en el juego, lo cual lo motiva a continuar.

Siguiendo la misma dirección, en el libro Pasajes: literatura, Bretz, Dvorak y Kirschner (1992) presentan una propuesta metodológica igualmente tradicional, que repite los problemas mencionados anteriormente. En cada capítulo, señalan aspectos lingüísticos específicos que les interesa puntualizar; luego desglosan una lista de vocabulario seleccionado; a continuación, transcriben un párrafo de la lectura y escriben preguntas como práctica de comprensión. En la segunda parte, proponen una aproximación al texto por medio de requerimientos como descripciones de los personajes, argumentos y a qué tipo de género pertenece el texto (por ejemplo, una telenovela, una novela de detectives, de ciencia ficción, historia de aventuras, romances, etc).

Por su parte, Belén González (2003: 1) en su artículo "El currículum integral en la enseñanza de la literatura" propone que a la hora de ofrecerle al alumno las lecturas debemos tomar en cuenta sus gustos y preferencias pero también la tradición cultural, esto es, las obras clásicas. Ahora bien, para no aburrir al lector, se sugiere ofrecer la posibilidad de leer una adaptación actual al castellano si la obra está escrita en un español antiguo. Además, afirma que para hacer llegar la literatura, y que el alumno se interese por ella, el profesor debe relacionarla con otras disciplinas u objetos como por ejemplo, el arte, una obra literaria y su película, serie, cómic, una ambientación del aula según la época literaria que se esté tratando, aunque sea con afiches de los autores o con portadas de las obras. "La forma de hacer más atractiva la literatura está asociada con el material que se utilizará, debemos recurrir a la variedad y a todos los recursos visuales que podamos tener".

Aunque es cierto que una buena ambientación contribuye a motivar la disposición de los alumnos, no es garantía de que se va lograr involucrar al estudiante activamente con la lectura y los textos. Ahora bien, relacionar los libros con obras artísticas, por ejemplo, es una 
buena estrategia para cautivar al estudiante, y puede resultar un recurso importante a la hora de complementar un análisis. Sin embargo, siguen faltando las herramientas teóricas que puedan ser utilizadas para continuar el estudio de la literatura.

A este respecto, Marcelo Flores y Susana López (2002: 1) señalan en su artículo "La importancia educativa de la enseñanza de la literatura" que la escuela es un lugar privilegiado para la formación en el mundo simbólico (éste les ayudará a comprender su realidad circundante) y para llegar a los símbolos la mejor ruta es la literatura; se busca entonces pasar de lo cotidiano a lo trascendental, especialmente por medio de la poesía. "El símbolo, como propósito, podría ser magistralmente enseñado a partir de la literatura y de allí que el estudiante entienda la realidad en la que vive” (Flores 2002: 1).

Aún sin negar la importancia del análisis simbólico, en esta posición, la literatura sigue siendo utilizada como medio. Lo primordial es el símbolo que ayude a comprender una realidad circundante y lo literario sigue estando relegado como objeto de estudio. Un punto rescatable es tratar de relacionar lo real con lo simbólico, ya que esto puede hacer más interesante el juego intelectual del lector con el texto.

Finalmente, un enfoque muy pertinente es el propuesto en el artículo “Recuperación: historia y enseñanza de la literatura”. Allí, Ángel Madriz (2000: 2) propone la necesidad de partir de la historia para tomar, recuperar de ella, aquellos aportes que los escritores o bien la obra misma, las críticas, las opiniones individuales o los movimientos y escuelas literarias pueden aportar y resultar de vital importancia para la conformación de una propuesta de enseñanza de lo literario, sin olvidar que desde esta propuesta pueda llegarse a la concepción de un modelo pedagógico que tome como elemento primordial el discurso mismo de la literatura.

En la propuesta anterior se toma a la literatura como objeto de estudio y se rescata su propio discurso, es decir, se circunscribe lo literario en el cuándo, el cómo y el dónde. Otro acierto es insistir en una relación con la historia que de alguna manera contestaría las preguntas anteriores. Sin embargo, el concepto de historia debe ampliarse y no limitarse solamente a los aportes de un escritor o un movimiento literario. El discurso es exterior pero abarca otros aspectos muy importantes como el porqué se escribe lo que se escribe, quién tiene derecho o no a hacerlo, la relación con el poder y otros factores importantes. "Lo literario, siempre en contexto, siempre rodeado de las explicaciones históricas, es decir, del movimiento que le dio vida se comprende mejor" (Madriz 2000: 2).

Dada esta situación, es indispensable proponer, en el presente trabajo de investigación, una nueva metodología para aproximarnos a la literatura que logre involucrar activamente al lector con el texto, jugando dinámicamente por medio de las estrategias textuales, brindándole al mismo tiempo elementos teóricos (en nuestro caso, claves culturales o deconstruccionismo) y contextos históricos que lo cautiven para analizar la literatura y continuar leyendo aun después de haber finalizado el curso. Se quiere convertir a los estudiantes hablantes no nativos en lectores regulares, motivados a estudiar la literatura y aumentar con esto su habilidad de lectura, eliminándoles en la medida de lo posible los estereotipos y actitudes negativas con las que se relaciona la literatura. 


\section{Propuesta metodológica}

Lo siguiente es una propuesta metodológica para la enseñanza de la literatura a estudiantes aprendices del español. En este sentido, se debe recalcar y tener claro que ésta no tiene como finalidad la enseñanza de la cultura latinoamericana, sino la enseñanza de la literatura, y a partir de ella, involucrar al estudiante hablante no nativo del español con los textos por medio de las teorías literarias y la historia para así motivarlo a la lectura y, con ello, como un círculo vicioso, despertar su interés en los textos. De esta forma, se ayuda al alumno a entender el porqué de algunas situaciones socioculturales, pero, ante todo, el papel trascendental de la literatura al reproducir y transmitir mitos, estereotipos y claves culturales que muestran y justifican ideológicamente la organización sociocultural latinoamericana. En otras palabras, es evidenciar la función ideológica de la literatura. En síntesis, no se trata de iniciar un proceso de "transculturación" o de "aculturación" en los estudiantes hablantes no nativos del español sino de brindar elementos para entender eventos cotidianos o excepcionales que ocurren en nuestros países y cómo los textos literarios son objetos de análisis al reformar, engendrar y transmitir lo que plasma la práctica social.

Con el fin de aclarar el punto anterior, es importante revisar la propuesta que hizo María Amoretti (2001: 1) en cuanto a una metodología interesante sobre cómo enseñar la cultura a alumnos extranjeros aprendices del español como segunda lengua, ya que ella utiliza algunos referentes teóricos que coinciden con los que se utilizarán posteriormente en nuestra propuesta. Con respecto a la enseñanza de la cultura, ella afirma que se debería partir de la noción de "identidad cultural" o "sujeto cultural". Esa noción implica la comprensión del proceso mediante el cual se llega a conformar la identidad hispanoamericana. Esto obliga a seleccionar materiales históricos, psicológicos y sociales con el propósito de crear un marco de referencia para nosotros mismos y, luego, formular hipótesis que expliquen eventualmente nuestras conductas frente al poder o la autoridad, frente a las reacciones que mantenemos con los demás y frente a las relaciones de género; frente a las dificultades de desarrollo o frente a nuestras producciones culturales en general.

En términos generales, Amoretti propone un enfoque filogenético donde se analiza el momento histórico enfocado en el nacimiento del sujeto colonial. Es decir, parte del análisis de la carta de Colón realizado por Cros para llegar a la conclusión de que la identidad latinoamericana es una identidad rota, difractada e híbrida. Esta hibridez se evidencia en diversos textos como en la pintura de Frida Kahlo, el realismo mágico presente en la literatura del boom latinoamericano y, finalmente, en hechos de la vida cotidiana. Esta ideología nos permite justificar o intentar una explicación válida de la realidad hispanoamericana.

Nuestra propuesta metodológica para la enseñanza de la literatura a estudiantes no nativos del español incluye también el estudio del sujeto colonial, básicamente por las mismas razones citadas con anterioridad. Sin embargo, no se debe perder de vista que el objeto de estudio va a ser la literatura y que el sujeto colonial se deberá estudiar como marco teórico para fundamentar el análisis de los textos. Como se desprende de lo anterior, lo primero que se debe tener claro es que para estudiar la literatura debemos partir de un marco teórico. La escogencia de este va a depender de los intereses y tópicos que el profesor decida enfatizar. Ahora bien, debido a que la explicación teórica es muy esquemática y es el profesor quien se recarga, se propone el análisis de diversas pinturas o ilustraciones paralelamente a las explicaciones teóricas con el fin de no sólo, valga la redundancia, ilustrar sino también de promover las 
oportunidades de interacción y participación de los estudiantes. Esto es fundamental ya que, de manera reiterativa, no se concibe llegar al análisis literario sin un marco teórico que fundamente y contextualice las afirmaciones que surjan al estudiar los textos.

Se considera pertinente partir del origen del sujeto colonial pues en él se originan tres claves culturales latinoamericanas muy importantes: colonial, búsqueda de identidad e hibridez. Ahora bien, al proponer lo anterior, tendremos entonces que iniciar con los aspectos históricos que propician el surgimiento de este sujeto. Sin los aspectos históricos es imposible explicar el origen del sujeto colonial y, por ende, establecer las claves culturales. Con este marco teórico se puede analizar un sinnúmero de textos; como sugerencia, podemos nombrar el cuento "La sequía" de Carlos Salazar Herrera, la novela Cien años de soledad de Gabriel García Márquez, el ensayo "La soledad de América Latina" del mismo autor, La casa de los espíritus de Isabel Allende, entre varias opciones.

En otras palabras, y de forma enfática, es fundamental ahondar en la historia oficial y no oficial para que al final de la explicación podamos delimitar muy claramente las tres claves culturales señaladas con anterioridad. Estas claves bien definidas y contextualizadas históricamente servirán de marco teórico para el análisis textual. Por medio de las claves culturales se pretende evidenciar en los análisis aspectos claves latinoamericanos presentes en los diferentes textos literarios seleccionados y trasmitidos por la función ideológica que posee la literatura.

Siguiendo esta línea y a modo de ejemplo, se puede recurrir a otro marco teórico para analizar diversos textos y que, además, resulta éste particularmente interesante por la clave que se desprende de él. Estamos hablando del deconstruccionismo, del cual utilizaremos especialmente su explicación sobre el origen de los centros y márgenes en Occidente. Esto nos dará una explicación clara de dónde se originan los ya nombrados centros y márgenes y lo que implica, por ejemplo, la oposición entre hombre / mujer y el resto de las oposiciones simbólicas que se desprenden de la anterior. No obstante, se debe recurrir, como se sugirió en los párrafos anteriores, a la historia para poder explicar el origen de la clave cultural que vamos a determinar y utilizar en este caso: machismo. Para tal efecto, se basará la explicación en la propuesta de Pierre Bourdieu sobre el origen del patriarcalismo en Occidente y el análisis histórico de las dos grandes vertientes que influyeron en este aspecto la cultura occidental: la tradición grecorromana y la tradición judeocristiana. Es decir, una vez explicado el origen de los centros en Occidente y expuesto el contexto histórico, se establecerá, entonces, la clave cultural.

Los textos que se pueden analizar a partir de este marco teórico son muchos; se recomiendan las crónicas coloniales de Tatiana Lobo del libro Entre Dios y el diablo, los poemas 15 y 19 de Pablo Neruda, las tradicionales leyendas "La Llorona" y "La Cegua", los cuentos de Ana Cristina Rossi en el libro Situaciones conyugales, la obra de teatro Hombres en escabeche de Ana Istarú, entre otros.

Tal y como se puede observar, la escogencia de estos marcos teóricos no es al azar; los análisis que se desprenden de la aplicación teórica pueden cautivar fácilmente al lector, involucrarlo en el proceso de lectura, motivarlo a leer más y encontrarle sentido práctico al esfuerzo intelectual que implica analizar un texto literario: una ventaja, una especie de ganancia de este esfuerzo, en este caso, sería comprender mejor la cultura latinoamericana por medio de sus claves culturales, poder dar cuenta de la organización de algunos grandes centros y márgenes en nuestros países y entender más la historia de Latinoamérica, lo cual 
convertiría al estudiante en un lector más competente para involucrarse de forma activa en el juego fascinante que se establece cuando una persona le da vida a un texto al iniciar el proceso de lectura.

Recapitulando, en el primer caso, se debe indagar en nuestras crónicas nuestras verdades (no la verdad) y, por ello, es necesario incluir la historia y hacer énfasis en los discursos fundantes de nuestra identidad, que generaron varios mitos y estereotipos. Finalmente, se establecen las claves culturales y, de allí, se toman los fundamentos para el análisis textual.

En el segundo ejemplo, se estudiará la teoría deconstruccionista para determinar el origen de los centros y los márgenes. Luego se enfocará el análisis en la oposición hombre / mujer para evidenciar la jerarquía. Seguidamente, se explicarán la propuesta de Bourdieu sobre el origen del patriarcalismo en Occidente y la influencia de las tradiciones judeocristiana y grecorromana. De allí se establecerá la clave cultural latinoamericana machismo. Sobre la base de esta teoría, se guiará el análisis textual.

Se propone, además, una clase introductoria que se basará en la teoría de la recepción para hacer énfasis en los estudiantes del papel activo del lector a la hora de analizar un texto literario, en la necesidad de un lector cada vez más competente (con más conocimientos) y su responsabilidad de un cincuenta por ciento de participación en el proceso de lectura. Para llegar a una propuesta que genere reflexión e interés, el lector debe trabajar en la construcción de la lectura, sin perder de vista que este trabajo es sobretodo placentero y gratificante.

En cada ejemplo, el objeto de estudio son textos literarios seleccionados específicamente, pues no se debe olvidar que el interés del trabajo es una propuesta de análisis literario; las teorías literarias, la historia y las pinturas o ilustraciones son herramientas complementarias para estudiar los textos literarios. La selección de estos fue hecha con base en un criterio de concordancia entre las claves que se estudian y el tema de los cuentos, el ensayo o las poesías. Esto debido a que se quiere guiar al estudiante para que vea las posibilidades de lectura pero fundamentadas, las posibilidades de análisis mucho más asertivas.

\section{Recomendaciones fundamentales a considerar para los planeamientos de clase}

1. Es indispensable incluir dentro de los planeamientos en los programas de español para extranjeros cursos de literatura latinoamericana, con tanta rigurosidad y especificidad como los de lengua.

2. Cuando se va a enseñar literatura, se debe tomar el texto (cuento, poesía, novela, drama o ensayo) como objeto de estudio. Si se va a utilizar la literatura como medio para enseñar la gramática, el léxico o aspectos culturales, debe aclararse este punto; en otras palabras, decir lo que se está haciendo tal cual es. Valga la reiteración, enseñar literatura es muy distinto a enseñar gramática, léxico, sintaxis o cultura. En los cursos de sintaxis española para hablantes nativos es frecuente que se utilice la literatura con el fin de ilustrar o practicar ciertas formas sintácticas, lo cual está muy bien, pero los estudiantes siempre tienen claro que están en un curso de sintaxis y no de literatura. Es fundamental hacer la misma diferencia en las clases para hablantes no nativos del español. 
3. En forma definitiva, el profesor de literatura necesita ser un profesional. Leer un cuento y buscar en él vocabulario nuevo, mostrar un adjetivo o resaltar una peculiaridad cultural no hace a una persona ser un profesor capacitado o entrenado académicamente para dar las lecciones de literatura. Se requiere que el profesor domine marcos teóricos y sepa cómo hacer un análisis textual; asimismo, debe conocer de las funciones de la literatura y de los movimientos históricos que han rodeado su producción y, por supuesto, enseñarlos.

Para analizar literatura es imprescindible tener un marco teórico para que la lectura esté fundamentada en algo más que suposiciones o ideas vagas. Ciertamente, la lectura que se desprenda del marco teórico no será ni mucho menos la única y la verdadera, pero sí será una que tenga un fundamento previo lo suficientemente investigado y reconocido como para hacer ver al estudiante la importancia y la seriedad del estudio literario.

\section{Sugerencias prácticas para la ejecución de la propuesta metodológica}

1. A la hora de enseñar literatura es importante considerar la población con la que estamos trabajando. Como son hablantes no nativos del español, es muy frecuente que tengan dudas sobre el vocabulario del texto. No se debe caer en el error de poner una lista de vocabulario extensa, porque se pierde el objetivo; los alumnos reciben demasiada información léxica fuera de contexto. Más recomendable es explicar una, dos o tres palabras que los estudiantes recordarán y no muchas que olvidarán rápidamente; además, se puede perder mucho tiempo en esto, tiempo valioso para enseñar los marcos teóricos y el análisis textual.

2. Muchas veces creemos que más es mejor. No siempre es así y, en el caso que nos compete, es preferible tomar un cuento y enseñar un marco teórico preciso para guiar con tiempo y claridad el análisis que saturar con muchos textos a los estudiantes y lograr el efecto contrario a lo que nos proponemos.

3. Cuando enseñemos un marco teórico, la claridad es fundamental. Poco se obtiene explicando de forma complicada y, mucho menos, utilizando terminología muy técnica. Lo importante es transmitir los conceptos claros y, para tal fin, podemos manejarlos con términos puntuales y sencillos. Por ejemplo, al utilizar nuestros marcos teóricos, se puede hablar básicamente de mitos, claves, opuestos, centros y márgenes. Recordemos que la elegancia está en la sencillez y la sabiduría también, podríamos agregar.

4. Al comenzar, se deben retomar los conceptos vistos en la clase anterior, especialmente los teóricos, porque sirven como repaso de las ideas importantes; al mismo tiempo, el alumno tendrá una directriz clara sobre el rumbo que tomará la lección que está por comenzar. El repaso debe ser breve y puntual.

5. Si estamos explicando mitos o algún otro concepto teórico, se debe hacer referencia constantemente a ejemplos de la realidad cotidiana. Con esto se logra interesar mucho a los alumnos, se hace más evidente lo que estamos hablando y hace de la teoría, propia del mundo de las ideas, "algo" concreto, que nos afecta en la vida práctica. 
6. Con respecto al análisis textual, se recomienda hacerlo primero en una clase. Los estudiantes deben conocer cómo debe realizarse, de modo que es necesaria la guía del profesor. Esta guía es insustituible, proporciona directrices claras y pautas a seguir. Después, el profesor puede asignar textos y pedir su análisis como tarea. Recordemos que la primera lección asignada al análisis textual no es suficiente para que un alumno adquiera todas las directrices necesarias. Por lo tanto, en clases posteriores, debemos brindar el espacio prudencial para que los estudiantes practiquen y mejoren lo que se les ha enseñado.

7. Al efectuar los análisis, tengamos presente enfatizar la función ideológica de la literatura. El evidenciarla hace más clara la importancia del estudio literario.

8. A la hora de ir enseñando cómo hacer el análisis textual, podemos recurrir a dos estrategias. Al comienzo, es recomendable guiar el análisis de forma oral. No obstante, en una segunda lección, se pueden formar grupos pequeños y, con ello, darles a los estudiantes el tiempo para discutir, comentar, señalar, pero con el profesor guiándolos. Esto va reforzando los procedimientos correctos y aclarando las dudas que vayan surgiendo. Conforme pasan las lecciones y el estudiante se vaya sintiendo más capacitado y seguro, se pueden incorporar otras actividades como debates o mesas redondas. Alternar la estrategia oral y grupal ayuda al dinamismo de la clase. En el mismo sentido, los análisis que se pidan como tarea pueden ser presentados en una exposición, o bien, ser entregados en forma de ensayo. De igual manera, hacer lo anterior ayuda a que la lección sea más interesante. Adicionalmente, se brinda la oportunidad de practicar varias destrezas propias del área de la lengua.

9. No desaprovechemos la oportunidad de hacer recomendaciones de otros textos (cuentos, novelas, poesías, ensayos o dramas). Esto hace germinar la semilla de la curiosidad y acrecentamos la inquietud por conocer, lo que a su vez contribuye a motivar la lectura. El simple hecho de haber escogido una obra específica para analizarla no significa que no podamos traer ejemplos y situaciones de otras narraciones y recomendar su lectura.

\section{Definición de una nueva destreza y su importancia}

Si nos aproximamos a una de las teorías literarias más útiles y funcionales, la teoría de la recepción, podremos entender en su plenitud la importancia del estudio de los textos, pero, sobre todo, el papel fundamental que tiene el lector. Iser Wolfgang (1984: 32), cuando analiza los procesos de lectura, hace un énfasis especial en la potencialidad del texto, es decir, en los significados por explorar que estos poseen. En este sentido, la literatura tiene un carácter virtual, no fijo y cobra vida cuando un lector la lee e interactúa con ella. Para lograrlo, el lector debe ser un, valga la insistencia, lector informado y tiene que involucrarse en el juego que se va a establecer entre él y el texto.

Antes de adentrarnos en lo que vamos a entender por lector informado, enfoquémonos en la palabra juego, en lo lúdico, que nos refiere a lo divertido, a lo interesante, a lo que nos absorbe, lo que nos atrae, lo que nos gusta y es un placer realizar. Así las cosas, debemos tener claro que lo que se establece entre un lector y un texto no es más que un juego, donde uno y otro tienen su parte y sus estrategias. Este juego es fundamental para, como bien lo dice 
Roland Barthes (1995: 121), gozar con y de la literatura. Todo va relacionado: el papel activo del lector, el involucrarse con los textos (para darles vida), el juego, el placer, el interés en la lectura y la motivación. Si recordamos el sistema de funcionamiento de los juegos, sabremos que la participación es fundamental y que yo como jugador trato de ir desarrollando mis habilidades para lograr mejores resultados y aumentar mis destrezas.

Ahora bien, retomemos la idea del lector informado. Todo conocimiento previo, tanto de lengua como cultural, histórico y de otros tipos, me hace un lector con más posibilidades y habilidades de juego con el texto; por lo tanto, me hace gustar más de la lectura, me intereso y participo cabalmente en lo que estoy haciendo. Desde esta perspectiva, el cuento, la novela o la poesía pueden tener muchas estrategias textuales, mucha belleza o cualidades para atraer mi atención, para hacer interesante mi juego; sin embargo, si soy un lector ignorante, sin mayor competencia, sin habilidades, no me voy a involucrar y la magia se va a quebrar.

Esta es una de las razones más fuertes para incluir dentro de los planeamientos diversos marcos teóricos. El aprendizaje no solo es literario; en este sentido, sería un aprendizaje histórico y cultural que llenaría la competencia, los marcos de referencia de los estudiantes. Se irían gestando así, en los alumnos, lectores cada día más informados, más hábiles y diestros para analizar cualquier texto que llegue a sus manos. Y no sería lo único por lograr; de hecho, estaríamos aumentando cada vez más las posibilidades de goce en el proceso de lectura, cautivándolos y motivándolos a leer.

La reflexión que lleva a la interpretación es altamente gratificante y el estudiante siente que su esfuerzo intelectual ha valido la pena. A su vez, ve que realiza un trabajo, que no pierde su tiempo y se toma con seriedad la nueva destreza que acaba de adquirir. En efecto, es una nueva destreza. Por lo tanto, se afirma que la propuesta metodológica para la enseñanza de la literatura del presente trabajo desarrolla una nueva destreza indispensable en los estudiantes de español como segunda lengua: la destreza analítica.

La metodología no solo enseña al estudiante de español como segunda lengua a estudiar la literatura sino que lo provee de marcos teóricos para utilizarlos como herramientas intelectuales que les sirven de marcos referenciales para desarrollar, claramente, esta destreza.

Así como en el campo de la enseñanza de la lengua se habla de las habilidades que se desarrollarán en un determinado planeamiento (la escucha, el habla, la lectura y la escritura), así también, en el campo de la enseñanza de la literatura, se puede afirmar que se desarrollará una habilidad específica: la habilidad reflexiva. Esta nace de los saberes, como los nombra Wolfgang, que tienen los textos literarios y las lecturas que se propongan. Las otras habilidades propias de los estudios de la lengua se pueden ir perfeccionando en una clase de literatura (y de hecho sucede), pero esto se tomará como una bonificación extra, una especie de ganancia externa. Lo importante es, dentro de nuestro planeamiento, potencializar la destreza analítica (e incrementar con ello la habilidad reflexiva), ambas tan necesarias, porque con ellas se está induciendo a los estudiantes a ser investigadores, a cuestionarse y, por ende, a ser arduos lectores.

Un nuevo campo de investigación ha sido abierto por cuanto esta nueva destreza, ya establecida, podría empezar a desarrollarse en los niveles intermedios bajos y altos o incluso desde los niveles principiantes. Este es un terreno inexplorado hasta el momento con un sinfín de posibilidades de investigación, altamente provechoso para los estudiantes. 


\section{Bibliografía}

Amoretti Hurtado, María. 2001. “Ontogénesis del sujeto cultural”. Antología del Curso Claves Culturales 1.

1993. "Hablemos del discurso". Kañina. Revista de Artes y Letras de la Universidad de Costa Rica. XVII (2): 209-212.

Anderson, Benedict. 2000. Imagined communities. New York: Verso.

Bados Ciria, Concepción. 2001. Textos literarios y ejercicios. Madrid: Ed. Anaya.

Barthes, Roland. 1995. La lección inagural. México D.F: Editorial Siglo XXI.

Bretz, Mary Lee et al. 1992. Pasajes. Estados Unidos: Mc GrawHill.

Bourdieu, Pierre. 2000. La dominación masculina. Barcelona: Editorial Anagrama.

Cros, Edmund. 1986. "Sociocrítica". Kañina. Revista de Artes y Letras de la Universidad de Costa Rica. 10: 96-100.

1995. D'un sujet a l'autre: sociocritique et psychanalyse. Montpellier: Edit du CERS.

Derrida, Jacques. 1971. De la gramatología. Buenos Aires: Siglo veintiuno.

1989. La deconstrucción en las fronteras de la filosofía. Barcelona: Ediciones Piados Ibérica, S. A.

1994. Márgenes de la filosofía. San José: Ediciones Cátedra.

Derrida, Jacques y Geoffrey Bennington. 1994. Jacques Derrida. Madrid: Ediciones Cátedra.

Láscaris, Constantino. 1961. Traducción Discurso del método. San José: Publicaciones de la Universidad de Costa Rica.

Lobo, Tatiana. 1999. Entre Dios y el diablo. Mujeres de la colonia. San José: Editorial Guayacán.

Macaya Trejos, Emilia. 1992. Cuando estalla el silencio. San José: Editorial de la Universidad de Costa Rica.

Neruda, Pablo. 2001. 20 poemas de amor y una canción desesperada. México: Editores Mexicanos Unidos, S.A. 
N. de Gallardo, Edelma. 1995. Guía práctica para enseñar español a extranjeros. San José: Litografía Codelca, S.A.

Real Academia Española. 1992. Diccionario de la Lengua Española. Vigésima primera edición. Madrid: Espasa.

Seley, David. 1994. Teaching Culture. Illinois: National Textbook Company.

Wolfgang, Iser. 1984. The reading process. New York: University Press Association.

Zeledón, Elías (Comp.). 1998. Leyendas costarricenses. Heredia: EUNA.

\section{Sitios web}

González, Belén. 20/02/2003. www. baseliteraria.3Id/ universitario.com. El currículum integral en la enseñanza de la literatura.

Flores, Marcelo y Susana López. 1 /02/ 2002. La importancia educativa de la enseñanza de la literatura. www. mx.groups.yahoo.com/ group/ upnqueretaro/.

Madriz, Ángel. 1998. Historia y enseñanza de la literatura. www.ucm.es/OTROS/especulo/ numero9/a madriz.html. 